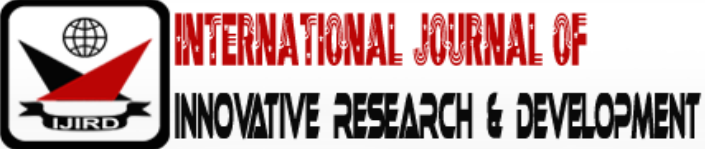

ISSN 2278 - 0211 (Online)

\section{School Gardening of Indigenous Vegetable as a Way of Improving Key Micro Nutrient Outcomes of Adolescents in Western Kenya}

Linda Sigilai
Nutritionist, Department of Nutritional Sciences, Kenya Nutritionists and Dieticians
Institute/ Masinde Muliro University of Science and Technology, Kenya
Dr. David Okeyo
CEO, Department of Chief Executive Officer,
Kenya Nutritionists and Dieticians Institute, Kenya
Asenath Sigot
Professor, Department of Nutritional Sciences,
Masinde Muliro University of Science and Technology, Kenya

\begin{abstract}
:
Globally, consumption of processed diets is rising with inadequate consumption of fresh vegetables and fruits. In East Africa nutritious diets are not affordable especially for adolescents. In Kenya there exists a barrier to intake of healthy diets including: limited knowledge of healthy food choices, poverty, and rapid growth of urban centers. The study sought to investigate school gardening of indigenous vegetables and its effect on knowledge, attitude and practice towards micronutrient rich diets among school students in Western, Kenya. The results of the study was improvement on knowledge of micronutrient rich foods, increased willingness to try new varieties of indigenous vegetable that are high in micronutrients, acquired cooking skills and increased involvement in school gardening of indigenous and exotic vegetables. In conclusion, school gardening of indigenous vegetables combined with nutrition education and vegetable preparation skills has the potential of improving intake of various micronutrients. Data on consumption of indigenous vegetables by the respondents' households should be further analyzed to show the home-based component.
\end{abstract}

Keywords: School gardening, indigenous vegetables, healthy diet, micronutrient rich food

\section{Introduction}

Malnutrition affects human health, resources, well-being, and similarly leads to substantial reduction of national and regional economic sW capacity, increase in school absenteeism and huge healthcare expenses (World Bank, 2006). WHO (2003) and FAO (2003), set the minimum vegetable and fruit intake per person per day at 400 grams. However, according to FAO food balance sheets, Kenya does not produce enough vegetable and fruits for her population despite having a suitable environment, only about 280 grams per capita per day of fruits and vegetables are available for human consumption (FAO, 2009). On average, the levels of iron, calcium, and vitamins contained in $100 \mathrm{~g}$ of fresh indigenous vegetables is enough to provide $100 \%$ of each nutrient required daily and $40 \%$ of proteins (Abukutsa, 2010 and Herforth, 2010). Despite the potential of indigenous vegetables to address micronutrient deficiencies and malnutrition, production and consumption is still low.

School-based garden interventions studies have shown improved, knowledge, attitude and intake of healthy food choices, but with most programs have targeting pre-school children and lower primary school going children, the secondary school students are left out missing on the benefits likely to be achieved by this intervention (Hutchinson et al., 2015).

\subsection{Overview of School Gardening and Nutrition Benefits of Indigenous Vegetables}

School garden programs refer to the kind of community gardens operated in the school setting with the aim of promoting social networks, relationships, and connectedness among students. Studies have indicated that an experience with nature improves students' cognitive levels; attention, performance and creates environmental awareness ((Mårtensson et al., 2009) and (Collado et al., 2013).

The benefits linked with high intake of vegetables and fruits are improved health and minimized risk of noncommunicable disease for all ages in the society (Heim, Stang \& Ireland, 2009). A study conducted in Kiambu, Kenya investigating the mineral and nutrition content of indigenous vegetables showed that they contain significant amounts of protein, sodium, iron and potassium and thus can reduce micronutrient and other nutrition deficiencies (Dushimama et al, 
2017). Another study in Ghana comparing the nutrient components of exotic and indigenous vegetables showed that cabbage and amaranths differ on the content of the following nutrients: energy (15kcals/49kcals), protein $(1.3 \mathrm{~g} / 9.4 \mathrm{~g})$, dietary fiber $(1.3 \mathrm{~g} / 3.3 \mathrm{~g})$, calcium $(36 \mathrm{mg} / 252 \mathrm{mg})$, iron $(0.86 \mathrm{mg} / 45.5 \mathrm{mg})$ the nutrient analysis of these vegetables show the potential of indigenous vegetables to tackle the coexistence of malnutrition, increasing obesity and high prevalence of non-communicable diseases in the society (Nyadanu \& Lowor 2015).School gardens also offer an opportunity for the students to increase their understanding of farming practices to produce food and improve their taste for varieties of foods (Blair, 2011; Ozer, 2015).

In addition to the health benefits of implementing school gardens, others that can be attained from the programs are lifestyle benefits such as acquiring of interpersonal relationships, leadership, social skills, team spirit, and problemsolving skills (Doerfler, 2011). School gardening interventions documented are limited in developing countries are limited. However, about 891 studies on school gardening have been carried out and documented in high income countries between January 2005 and October 2015 (Savoie-Roskos, Wengreen \& Durward, 2017).

\section{Methods}

The research was conducted using experimental design; five mixed day schools were purposively selected in Kakamega County. 100 secondary school students were randomly selected from the mixed day high schools. Collection of data involved use of pre and posttest questionnaires. Data analysis was done using SPSS inferential statistics for within group Z scores and between time Z scores were used. Descriptive statistics, mode, median, and means were used to analyze continuous variables

\section{Results}

\subsection{Nutritional Knowledge of the Respondents on Indigenous Vegetables}

In this study knowledge was defined as good and poor knowledge based on the score of; identification of food groups, color of the vegetables, nutrition benefits, minerals and vitamins contained and typical serving size for fruits and vegetables .A correct score of 4 and above on this indicators was graded as good knowledge, while a score of 3 and below was graded as poor knowledge. $89 \%$ at posttest had improved knowledge compared to $72 \%$ on indigenous vegetables and other food sources high in key micronutrients.

On obtaining information on nutrition education at the beginning of the study, only $11 \%$ had participated in nutrition education forums while $88 \%(\mathrm{z}=7.56, \mathrm{CI}=0.78-0.97)$ had scanty information. This improved significantly by the end of the study $70 \%(\mathrm{z}=4.0, \mathrm{CI}=0.60-0.80)$ had received nutrition education and information about micronutrient rich foods while $30 \%(\mathrm{z}=4.0, \mathrm{CI}=0.20-0.40)$ still did not have adequate information. Posttest, the topics most respondents were conversant with were: Both food groups and nutritional benefits of indigenous vegetables at $45 \%(\mathrm{z}=3.98, \mathrm{CI}=0.35-0.55)$, $18 \%$ understood food groups more $(\mathrm{z}=1.39, \mathrm{CI}=0.08-0.28)$, health benefits of fruits and vegetables consumption $(\mathrm{z}=2.58$, $\mathrm{CI}=0.02-0.22)$ while the remaining $30 \%(\mathrm{z}=0.99, \mathrm{CI}=0.20-0.40)$ did not have information about any topics covered.

Secondary school going students being in their adolescent years, Iron is the main micronutrient of concern among this study group. On knowledge of iron deficiency anemia; 88\% ( $\mathrm{z}=7.56, \mathrm{CI}=0.78-0.98)$ of respondents were aware of existence of iron deficiency anemia, while $11 \%(z=7.76, C I=0.01-0.21)$ were not aware.

\subsection{Attitude of the Respondents towards Indigenous Vegetables}

At the beginning of the study, a significant majority $78 \%$ of the students liked indigenous vegetables $(\mathrm{z}=8.95$, $\mathrm{CI}=0.68-0.87$ ), $11 \%$ reported a little liking, while $10 \%$ reported no liking at all. At the end of the study $90 \%$ liked the vegetables and were willing to consume more while $10 \%$ reported little liking. On willingness to try new varieties of Indigenous vegetables, at the beginning of the study, $53 \%$ were willing, while $46 \%$ were unwilling by the end of the study $93 \%$ were willing while $7 \%$ were still unwilling. On the specific types of the vegetables, most of the Indigenous vegetables seemed to be available in the area however, it terms of consumption cowpea was consumed at $96 \%$, black nightshade at $89 \%$, jute plant at $89 \%$, amaranth at $82 \%$, pumpkin leaves at $82 \%$, sunhemp at $84 \%$ and spider plant recorded lowest consumption at $77 \%$. Majority of the students preferred the taste of cowpea at $88 \%$, black nightshade at $80 \%$, pumpkin leaves at $74 \%$, sunhemp at $73 \%$, jute plant at $72 \%$, amaranth at $69 \%$, while spider plant recorded the least preference at $60 \%$.

At the beginning of the study the bitter taste of some indigenous vegetables was mentioned to be a significant hindrance to its consumption at $60 \%(\mathrm{z}=5.37, \mathrm{CI}=0.50-0.69)$, lack of cooking skills and limited recipes for the vegetables was also a reason for $25 \%$ of the respondents lacking interest in the vegetable. Somehow $15 \%$ developed negative attitudes due to that fact that they were force-fed on same varieties of the vegetables at a tender age. By the end of the study with the preparation of the vegetables together with the participants, $95 \%$ of the participants like the taste of Indigenous vegetables, $5 \%$ still felt it was bitter.98\% of the respondents had acquired cooking skills for preparation of the vegetables. Consumption of general diets apart from the indigenous vegetables was also affected by several factors; availability $39 \%$, nutritional knowledge $22 \%$, taste $20 \%$, affordability $10 \%$, preparation time $8 \%$. Generally, intake of fruits and vegetables by respondents in the household was high with $91 \%$ increasing their intakes while $5 \%$ still had low consumption.

\subsection{Production and Consumption Practices of Respondents to Indigenous Vegetables}

Study findings showed (100\%) of respondents had a school garden. At the beginning of the study, the purposes the purposes of the gardens were for examinable agriculture projects $80 \%(z=5.97, C I=0.70-0.90)$, while $19 \%(z=6.17$, 
$\mathrm{CI}=0.09-0.29$ ) was used for growing other food crops for consumption within the school students for beneficial projects. At the end of the study, $71 \%(\mathrm{z}=4.19, \mathrm{CI}=0.61-0.81)$ of the gardens were still used for examinable projects while $29 \%(\mathrm{z}=$ 4.17, $\mathrm{CI}=0.19-0.39$ ) was used for growing other food groups including vegetables. On involvement in school gardening at the beginning of the study $68 \%(\mathrm{z}=3.58, \mathrm{CI}=0.58-0.78)$ of students had participated in school gardening while $32 \%(\mathrm{z}=$ $3.58, \mathrm{CI}=0.22-0.42)$ were not involved, by the end of the study majority of the respondents $98 \%(\mathrm{z}=9.55, \mathrm{CI}=0.88-1.08)$ participated actively in the school gardening.

Concerning vegetable production, in the schools at the beginning of the study $80 \%(\mathrm{z}=5.97, \mathrm{CI}=0.70-0.90)$, produced exotic vegetables only, $20 \%(\mathrm{z}=5.97, \mathrm{CI}=0.10-0.30)$ produced both exotic and indigenous vegetables. By the end of the study $82 \%(\mathrm{z}=9.75, \mathrm{CI}=0.72-0.92)$ produced both exotic and indigenous vegetables, $11 \%(\mathrm{z}=4.38, \mathrm{CI}=0.01-0.21)$ of the schools produced only exotic vegetables, $7 \%(z=5.17, C I=0.03-0.17)$ only indigenous vegetables. At the beginning of the study, farm produce in the school was mainly consumed by teachers and members of staff $76 \%$ ( $\mathrm{z}=8.56, \mathrm{CI}=0.66-0.86)$, the respondents $14 \%(z=3.78, C I=0.04-0.24)$ had consumed what was produced in the school gardens and the remaining $9 \%(\mathrm{z}=4.78, \mathrm{Cl}=0.01-0.19)$ was consumed by students, teachers and members of staff. At the end of the study $90 \%$ $(\mathrm{z}=7.96, \mathrm{CI}=0.80-1.0)$ of the vegetables produced in the school was consumed by students, members of staff and teachers while $10 \%(z=7.96, C I=0.00-0.20)$ was for only teachers and members of staff. The production of indigenous vegetables back at home by the respondents increased from $39 \%(\mathrm{z}=2.19, \mathrm{CI}=0.29-0.49)$ at the beginning of the study to $53 \%$ $(\mathrm{z}=0.60, \mathrm{CI}=0.43-0.63)$ at the end of the study. On types of indigenous vegetables produced in the households of the respondents, $73 \%(z=7.96, C I=0.63-0.83)$ produced more than 4 types of Indigenous vegetables while $14 \%(z=3.78$, $\mathrm{CI}=0.04-0.24)$ produced 2-4 types and $13 \%(\mathrm{z}=3.98, \mathrm{CI}=0.03-0.23)$ produced between $1-3$ different types of Indigenous vegetables.

On consumption of the various types of indigenous vegetables,97\% of the respondents had ever consumed cowpeas, $83 \%$ had ever consumed amaranth, $83 \%$ had also ever consumed pumpkin leaves $89 \%$ had ever consumed black nightshade, 84 (84.8\%) had ever consumed sun hemp (miro), 89 (89.9\%) had ever consumed jute plant (more). 59\% of respondents consumed amaranth once a week while $24 \%$ had it twice a week. $75 \%$ purchased the amaranth consumed while $24 \%$ produced enough for the household. Pumpkin leaves were consumed once a week by the majority (58\%) of the respondents while, $23 \%$ consumed it twice a week.67\% purchased the pumpkin leaves, while $32 \%$ produced enough for the household.

According to the respondents, $79 \%$ consumed indigenous vegetables because of the belief that it improves health/nutrition, while $8 \%$ consumed it because of its taste, $5 \%$ availability, $5 \%$ tradition $2 \%$ price. Concerning the reasons for reduced consumption of indigenous vegetables currently compared to old times, $36 \%$ could not easily get the vegetables and the lack of availability of the vegetables in the market deterred them from consuming it, $29 \%$ of the respondents indicated that the high prices of the vegetables prevented increased consumption, the taste of the vegetables was a factor for reduced consumption for $21 \%$ of the respondents. Consumption of general diets apart from the indigenous vegetables was also affected by several factors; availability $39 \%$, nutritional knowledge $22 \%$, taste $20 \%$, affordability $10 \%$, preparation time $8 \%$. In $43 \%$ of the household mothers decided on the food to be consumed, in $27 \%$ of household decisions on food to be consumed was done by all family members, and in another $25 \%$, both father and mother made the decisions.

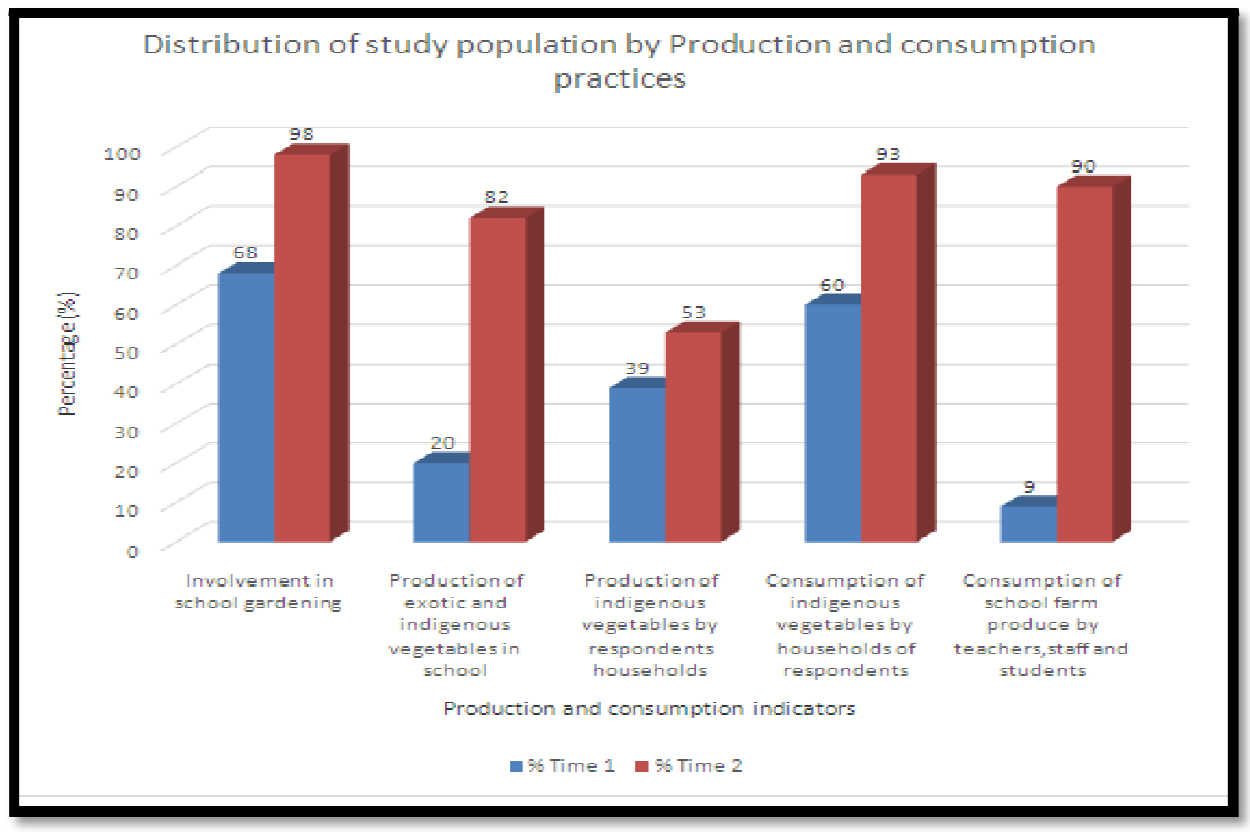

Figure 1 


\section{Discussions}

\subsection{Nutritional Knowledge of the Respondents on Indigenous Vegetables}

Local knowledge especially where the food is of indigenous origin affects the knowledge of the health benefits of that food (Keller 2004,Onyango 2015).Studies on school-based nutrition education implementation showed an increase in Knowledge, attitude and practices and improved students' nutritional status(Agdeppa et al 2019).Another study that involved school gardening as a component of nutrition education showed that nutrition education and dietary habits of the participants was higher than the non-participants(Parmer., 2009).This study finding showed a 59\%(11 \% to 70\%) increase in the number of participants engaged in nutrition education by the end of the study and $17 \%$ ( $72 \%$ to 89 ) increase in knowledge. These findings agree with those of a previous study that associated school gardening led by external specialists with greater number of vegetables recognition as compared to teacher led gardening. (Hutchninson et al., 2015)

The Global Nutrition Report 2018, showed that Anemia had risen globally by 32.8\% among adolescent girls, this is attributed to poor diets that hinder achievement of nutrition targets (WHO, 2019). Jamali, Mahesar \& Bhutto (2016) in a study involving school going students pin points the fact that anemia is a public health problem especially in school age students with a range of adverse effects including, poor cognitive performance, poor development, impairment of physical capacity, low work performance of adolescents and poor immunity among others. This study findings did not show any changes in knowledge, causes and diets that relate to iron deficiency anemia .This is in contrast to a similar study that showed that intervention with indigenous foods leads to improved knowledge and decline in micronutrient deficiencies (Gotor and Irungu, 2010).There is need to effectively implement nutrition education programs which inculcate healthy eating habits and proper cooking practices and address the students' needs (Yeung, 2010).

\subsection{Attitude of the Respondents towards Indigenous Vegetables}

The attitude towards indigenous foods in Africa have been negative since colonial era and this has led to a decline in food diversity and narrowing in diets (Frison, et al.,2010).Closer home in Tanzania negative perceptions that exist have led to reduction in the value of Indigenous vegetables and their consumption in diets from $20 \%$ to $11 \%$ as a proportion of the total value of food in diets (Ambrose-Oji, 2012). This study finding was contrary to other findings as $12 \%$ ( $78 \%$ to $90 \%$ ) of the respondents changed their attitude towards Indigenous vegetables and there was a $40 \%$ increase in willingness to try new varieties of Indigenous vegetables. Despite the differences with other studies in terms of attitude of school going students towards Indigenous vegetables, these findings are similar to a study by Cooke which showed that preference and liking towards fruits and vegetables by school going students are determined by the extent to which it is familiar. All in all, students enjoy what is familiar (Cooke, 2007).

In a previous study lack of cooking skills, bitter taste of indigenous vegetables among other factors have been attributed to low intake of indigenous vegetables among school going students (Krolner et al., 2011). The findings of this study showed a decline in the bitter taste of some indigenous vegetables by $55 \%$ and $78 \%$ had acquired cooking skills. The findings of this study agree with recommendations made previously suggesting that effective implementation of nutrition education programs and awareness campaigns that inculcate healthful eating habits and encourage the intake of traditional vegetables, including proper cooking and preservation practices as a means of preventing loss of indigenous knowledge and minimizing the negative attitude towards traditional vegetables (Yeung, 2010; Dweba \&_Mearns, 2011).

\subsection{Production and Consumption Practices of the Respondents on Indigenous Vegetables}

Global focus on improving adolescent nutrition has changed to their diets and health habits as evidence shows that addressing nutrition problems during adolescence can be important for catch up growth, improved cognition and reduced risk of future NCDs, the report suggests inclusion of voices and experiences of adolescents as a means of effective solutions (WHO,Global Nutrition report, 2018).Despite the contribution of indigenous vegetables and other traditional crops to food and nutrition security in Kenya, production is low(Muthoni and Nyamongo,2010). This study findings recorded a 30\% (68\% to 98\%) improvement in the involvement in school gardening and production of indigenous vegetables.

Providing individuals with more opportunities to learn about fruit and vegetables has the ability to improve their consumption. These practices can be integrated into family life practices if the intervention group identifies more value, importance, and relevance of the fruit and vegetable Information (Gerstein et al 2010). In this study the consumption improved by $81 \%$ (9\% to $91 \%$ ) within the school and $33 \%$ (60\% to 93\%). In contrast to the findings of this study, Christian et al, (2014) found little evidence that could be used to support the arguments that school gardening programs alone can enhance student's daily consumption of fruits and vegetables. Hence increased intake observed in this study may be attributed to inclusion of other interventions in the study that included nutrition education and cooking skills.

Different studies report varied findings on the effect of interventions on consumption improvement, other studies report, similar observations were by Wang et al., (2010) found that there was a statistically significant difference between students who were most and least exposed to the intervention. The former had increased their fruits and vegetables consumption by 0.5 cups while the latter only increased by 0.3 cups. In a study by Savoie-Roskos, Wengreen \& Durward (2017) out of the 14 articles reviewed, 10 articles determined that there was statistically significant increase in fruits or vegetables consumption among participants after the effective implementation of a gardening intervention. However, a similar study (Hanbazaza et al., 2015) reported no consumption of fruits and vegetables consumption at home even after improvement on knowledge and preferences of the two at school and as a result it was suggested that complementing 
school-based programs with home based components may be necessary to successfully influence students' consumption of fruits and vegetables.

\section{Conclusions and Recommendations}

\subsection{Nutrition Knowledge of the Respondents on Indigenous Vegetables}

This study has established that setting up an intervention with a focus on school gardening, nutrition education and preparation Significantly improved knowledge on indigenous vegetables including; identification of different types of Indigenous vegetables, awareness of nutrition value of Indigenous vegetables, the different food groups, choice of healthy diets.The study findings on iron deficiency anemia showed no difference at the end of the study in the knowledge, signs and causes of the deficiency, the sources of iron in diets and factors that hinder iron absorption. Iron being a micronutrient of concern for secondary school students especially adolescent girls, this study findings show limited knowledge on the subject matter.

\subsection{Attitude of the Respondents towards Indigenous Vegetables}

Generally, on attitude, the study findings showed an improvement in the secondary school students towards indigenous vegetables. Indicators on taste perceptions towards Indigenous vegetables, preparation of Indigenous vegetables and willingness to try different varieties of Indigenous vegetables were attitude indicators that showed improvement after the study intervention. Additionally, involvement of both male and female secondary school students in both gardening and preparation is significant in this study as literature on indigenous crops in Africa shows women as taking the lead in the roles of preparation of indigenous vegetables and men consider these foods as belonging to women and students. The study generally shows that there is an improvement in the perceptions of young consumers in regard to indigenous vegetables.

\subsection{Production and Consumption of the Respondents on Indigenous Vegetables}

There was a significant increase in production of both exotic and indigenous vegetables in the school gardens. The study findings also showed increased intake of indigenous vegetables among the respondents, the consumption of the school farm produce among teachers, staff and students also improved. The household consumption of vegetables also improved. The findings show how a combination of school gardening and combination of other interventions like in this study the inclusion of nutrition education to improve knowledge and increasing familiarity with the vegetables, increased production and consumption of micronutrient rich foods.

\subsection{Recommendations of the Study}

The following are the recommendations to the different stakeholders interested in promoting the nutrition and health of school going students and in increasing consumption and production of indigenous vegetables

\subsection{Recommendations for Policy}

- Agriculture and education ministries or relevant stakeholders to institute gardening programs both in school set up and linkage with community gardens that would provide direct and indirect support by encouraging increased production and consumption of Indigenous vegetables and other fresh and healthy fruits and vegetables.

- Learning institutions curriculum should comprehensively provide the learners with nutrition education and create awareness on the existing deficiencies and diseases and their prevention.

- Government should implement the existing school health policy to ensure the desired improvement especially on the nutrition of students in learning institutions.

\subsection{Recommendations for Practice}

More public health awareness campaigns targeting the secondary school students and caregivers be conducted within school and community settings to address the nutrition and health issues arising at adolescence and adulthood

\subsection{Recommendations for Future Research}

- Future studies could conduct research on knowledge, attitude and practice towards Indigenous vegetables from different settings, as well as longitudinal studies. This in turn could help us identify how the different varieties of Indigenous vegetables in the different regions compare in terms of knowledge and consumption.

- Future researchers could study the effect of cooking process on the nutrient content of Indigenous vegetables

- Future research should survey both secondary school students and their parents, instead of solely the school students. Surveying parents in addition to school students would help document the effect of intervention at the household level clearly.

\section{References}

i. Ambrose-Oji, B. (2009). Urban Food Systems and African Indigenous Vegetables: Defining the Spaces and Places for African Indigenous Vegetables in Urban and Peri-Urban Agriculture Urban food systems and trends in vegetable production in urban. In African indigenous vegetables in urban agriculture (pp. 33-66). Routledge. 
ii. Abukutsa, M. O. O. (2010). African indigenous vegetables in Kenya: Strategic repositioning in the horticultural sector. Jomo Kenyatta University of Agriculture and Technology.

iii. Angeles-Agdeppa, I., Monville-Oro, E., Gonsalves, J. F., \& Capanzana, M. V. (2019). Integrated school-based nutrition programme improved the knowledge of mother and schoolchildren. Maternal \& child nutrition, 15, e12794.

iv. Blair, D. (2009). The child in the garden: An evaluative review of the benefits of school gardening. The journal of environmental education, 40(2), 15-38.

v. Christian, M. S., Evans, C. E., Nykjaer, C., Hancock, N., \& Cade, J. E. (2014). Evaluation of the impact of a school gardening intervention on children's fruit and vegetable intake: a randomised controlled trial. International Journal of Behavioral Nutrition and Physical Activity, 11(1), 99.

vi. Collado, S., Staats, H., \& Corraliza, J. A. (2013). Experiencing nature in children's summer camps: Affective, cognitive and behavioural consequences. Journal of Environmental Psychology, 33, 37-44.

vii. Cooke, L. (2007). The importance of exposure for healthy eating in childhood: a review. Journal of human nutrition and dietetics, 20(4), 294-301.

viii. Doerfler, H. A. (2011). Using school gardens as a vehicle for health promotion for elementary school youth: a review of the literature (Doctoral dissertation, University of Pittsburgh).

ix. Dushiminana, C., Nemerimana, A., Pierre, C., Pierre, J., Habineza, M., Mungai John (2017) Nutritional content of certain indigenous vegetables for food insecurity malnutrition reduction in Kiambu County, Kenya.research gate.

x. Dweba, T. P., \& Mearns, M. A. (2011). Conserving indigenous knowledge as the key to the current and future use of traditional vegetables. International Journal of Information Management, 31(6), 564-571.

xi. Frison, E., Smith, I. F., Cherfas, J., Eyzaguirre, P., \& Johns, T. (2005). Using biodiversity for food, dietary diversity, better nutrition and health. South African Journal of Clinical Nutrition, 18(2), 112-114.

xii. Fanzo, J., Hawkes, C., Udomkesmalee, E., Afshin, A., Allemandi, L., Assery, O., ... \& Corvalan, C. (2018). 2018 Global Nutrition Report: Shining a light to spur action on nutrition.

xiii. Gerstein, D. E., Martin, A. C., Crocker, N., Reed, H., Elfant, M., \& Crawford, P. (2010). Using learner-centered education to improve fruit and vegetable intake in California WIC participants. Journal of nutrition education and behavior, 42(4), 216-224.

xiv. Gotor, E., \& Irungu, C. (2010). The impact of Bioversity International's African leafy vegetables programme in Kenya. Impact Assessment and Project Appraisal, 28(1), 41-55.

xv. Hanbazaza, M. A., Triador, L., Ball, G. D., Farmer, A., Maximova, K., Nation, A. F., \& Willows, N. D. (2015). The impact of school gardening on Cree children's knowledge and attitudes toward vegetables and fruit. Canadian Journal of Dietetic Practice and Research, 76(3), 133-139.

xvi. Heim, S., Stang, J., \& Ireland, M. (2009). A garden pilot project enhances fruit and vegetable consumption among children. Journal of the American Dietetic Association, 109(7), 1220-1226.

xvii. Herforth, A. (2010). Nutrition and the Environment: Fundamental to Food security in Africa. Chapter 7. The African Food System and its Interaction in Human Health and Nutrition. Ed Per Pinstrup-Andersen. Cornell University Press, New York.

xviii. Hutchinson, J., Christian, M. S., Evans, C. E. L., Nykjaer, C., Hancock, N., \& Cade, J. E. (2015). Evaluation of the impact of school gardening interventions on children's knowledge of and attitudes towards fruit and vegetables. A cluster randomised controlled trial. Appetite, 91, 405-414.

xix. Jamali, N. H., Mahesar, H., \& Bhutto, M. A. (2016). Prevalence of Iron Deficiency Anaemia in School and College Going Students of District Shaheed Benazirabad Sindh Province, Pakistan. Open JBloodDis, 6, 67-78.

xx. Keller, G. (2004). African nightshade, eggplant, spiderflower et al.-production and consumption of traditional vegetables in Tanzania from the farmers point of view. Masterarbeit im wissenschaftlichen Studiengang Agrarwissenschaften an der Georg-August Universität Göttingen, Fakultät für Agrawissenschaft.

xxi. Krølner, R., Rasmussen, M., Brug, J., Klepp, K. I., Wind, M., \& Due, P. (2011). Determinants of fruit and vegetable consumption among children and adolescents: a review of the literature. Part II: qualitative studies. International Journal of Behavioral nutrition and physical activity, 8(1), 112.

xxii. Mårtensson, F., Boldemann, C., Söderström, M., Blennow, M., Englund, J. E., \& Grahn, P. (2009). Outdoor environmental assessment of attention promoting settings for preschool children. Health \& Place, 15(4), 11491157.

xxiii. Muthoni, J., \& Nyamongo, D. O. (2010). Traditional food crops and their role in food and nutritional security in Kenya. Journal of Agricultural \& Food Information, 11(1), 36-50.

xxiv. Onyango, A. African indigenous vegetables in Kenya. Available: researchgate. net.

xxv. Ozer, E. J. (2007). The effects of school gardens on students and schools: Conceptualization and considerations for maximizing healthy development. Health Education \& Behavior, 34(6), 846-863.

xxvi. Parmer, S. M., Salisbury-Glennon, J., Shannon, D., \& Struempler, B. (2009). School gardens: an experiential learning approach for a nutrition education program to increase fruit and vegetable knowledge, preference, and consumption among second-grade students. Journal of nutrition education and behavior, 41(3), 212-217.

xxvii. Savoie-Roskos, M. R., Wengreen, H., \& Durward, C. (2017). Increasing fruit and vegetable intake among children and youth through gardening-based interventions: A systematic review.Journal of the Academy of Nutrition and Dietetics, 117(2), 240-250.

xxviii. World Bank, W. (2006). Repositioning Nutrition as Central to Development: A Strategy for Large-Scale Action.World Bank. (2007). from agriculture to nutrition: pathways, synergies, and outcomes. Technical report, Washington (DC). 
xxix. World Health Organization. (2019). Nutrition in universal health coverage (No. WHO/ NMH/ NHD/ 19.24). World Health Organizatio

xxx. Yeung, W. L. T. L. (2010). Gender perspectives on adolescent eating behaviors: a study on the eating attitudes and behaviors of junior secondary students in Hong Kong. Journal of nutrition education and behavior, 42(4), 250-258. 